\title{
EFEITO ALELOPÁTICO DE CARQUEJA, CONFREI E MIL-FOLHAS SOBRE O DESENVOLVIMENTO DA TIRIRICA
}

\author{
A llelopathic effect of the carqueja, comfrey and yarrow on the development of nutgrass
}

\author{
Letícia Regina Branco Gaziria, Ruy Inacio N eiva de Carvalho ${ }^{b}$ \\ a Engenheira A grônoma, Curitiba, PR - Brasil, e-mail: legaziri@ yahoo.com.br

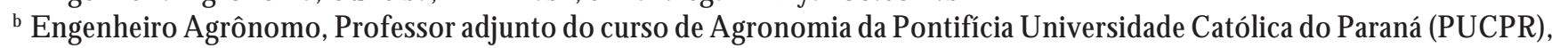 \\ São José dos Pinhais, PR, Brasil, e-mail: ruy.carvalho@ pucpr.br
}

\begin{abstract}
Resumo
O presente trabalho teve por objetivo avaliar o efeito alelopático da carqueja, confrei e milfolhas sobre o desenvolvimento da tiririca. Os experimentos foram realizados em casa de vegetação com irrigação automática e as diferentes formas de aplicação das plantas estudadas foram: plantas picadas e incorporadas ao substrato; plantas picadas e adicionadas em cobertura do substrato; aplicação de extrato bruto aquoso (EBA) no substrato; e aplicação em cobertura do resíduo da obtenção do EBA. O EBA foi obtido por turbilhonamento das plantas medicinais em liquidificador (200 g. $\left.\mathrm{L}^{-1}\right)$, utilizando-se $30 \mathrm{~mL}$ do extrato por embalagem. No tratamento resíduo do extrato foram utilizados os resíduos das plantas retidos em peneira após a passagem do extrato aquoso. Para os tratamentos incorporado, resíduo e cobertura foram utilizados $6,1 \mathrm{~g}$ de plantas por embalagem. $\mathrm{O}$ substrato utilizado foi a areia e foram plantados dois tubérculos de tiririca por embalagem. Os tratamentos foram avaliados por 60 dias. Após esse período concluiu-se que a planta de mil-folhas não apresentou efeito alelopático inibidor, apresentando, para o tratamento incorporado, estímulo à emissão de folhas por planta de tiririca em relação à testemunha. A planta de carqueja, para os tratamentos incorporados, em cobertura e resíduo do extrato bruto aquoso, proporcionou menor porcentagem de emergência e menor número de folhas por planta de tiririca em relação à testemunha. Plantas de confrei nos tratamentos resíduo do extrato e extrato bruto aquoso reduziram a porcentagem de emergência de tiriricas sem apresentar estímulo à emissão de folhas na planta.
\end{abstract}

Palavras-chave: Alelopatia. A chillea millefolium. Baccharis trimera. Cyperus rotundu. Symphytum officinale. 


\begin{abstract}
The present work aims to evaluate the allelopathic effect of the carqueja, comfrey and yarrow ("thousand leaves" in botanical Latin) on the nut grass. The experiments were performed in a house with automatic irrigation and the different forms of the plants studied were: bitten plants incorporated to the substrate; bitten plants added to the substrate cap; application of crude aqueous extract (EBA) on the substrate; and application on residue cap obtained from EBA. EBA was obtained by means of whirling movements of the medicinal plants in a blender (200 $\left.g . L^{-1}\right)$, and $30 \mathrm{~mL}$ was utilized from the extract per packaging. On treating the extract residue, the residue of the plants was retained in a sieve after the passage of the aqueous extract. For the incorporated treatment, residue and cap were used, $6.1 \mathrm{~g}$ of plants per packaging. The substrate utilized was sand and two tubers of nut grass were planted per packaging. The treatments were evaluated for 60 days. After such period, it was concluded that the yarrow plant did not present any allelopathic inhibitor effect, and presented, for the incorporated treatment, stimulus to the emission of leaves per nut grass plant in relation to testimony to it. The carqueja plant, for the incorporated treatments, on cap and residue of the crude aqueous extract, provided less emergency percentage and less leaves per nut grass plant in relation to the testimony. Comfrey plants in extract residue and crude aqueous extract treatments reduced the emergency percentage of the nut grass, and did not present stimulus to the emission of leaves in the plant.
\end{abstract}

Keywords: Allelopathy. Achillea millefolium. Baccharis trimera. Cyperus rotundus. Symphytum officinale.

\title{
INTRODUÇÃO
}

Nas lavouras de plantas medicinais está proibido o uso de agrotóxicos, o que faz com que os produtores busquem outras formas de controle que não prejudique o meio ambiente, não contamine as plantas cultivadas e maximize a sua produção final.

A alelopatia vem sendo muito estudada com o propósito de se complementar os tradicionais métodos de controle de plantas daninhas (G O MID E, 1993), pois a utilização de herbicidas, em muitos casos, é a única alternativa para o seu controle. Um exemplo é a tiririca, pois, segundo Magalhães e Franco (1962), cerca de 20\% de seus tubérculos localiza-se entre 15 a $40 \mathrm{~cm}$ de profundidade, dificultando o uso de práticas culturais convencionais.

A alelopatia pode ser definida como a interferência positiva ou negativa de compostos do metabolismo secundário produzidos por uma planta (aleloquímicos) e lançados ao meio (FERREIRA, 2004). $O$ modo de ação dos aleloquímicos pode ser dividido em ação direta e indireta, incluindo-se alterações nas propriedades do solo e na atividade dos microrganismos (FERRE IRA; ÁQ UILA, 2000). Os aleloquímicos podem ser alternativas para a produção de herbicidas ambientalmente desejáveis com novos sítios moleculares de ação (SO UZA FILHO; ALVES, 2002).

Há registros no Brasil de casos de culturas exercerem efeitos sobre outra como na rotação de culturas. Os restos da cultura de trigo retardaram o crescimento de plantas de algodão ou de arroz em rotação (FERREIRA; AQUILA, 2000). As plantas de soja ou azevém inibiram o desenvolvimento das raízes de milho em até 34\% (MARTIN; MCCOY; DICK, 1990).

Também no lado da agricultura, as plantas medicinais vêm sendo estudadas pelos seus efeitos alelopáticos visando à redução do uso de agrotóxicos de uma forma economicamente viável. D esta forma, atende-se aos requisitos da sustentabilidade da produção agrícola, pois se trata de um manejo tecnicamente correto e ambientalmente seguro.

A tiririca (Cyperus rotundus L.) é uma das plantas daninhas mais difíceis de serem controladas pelas práticas culturais convencionais (MAGALHÃES; FRANCO, 1962). Segundo Lorenzi (2000), a 
tiririca é uma planta A ngiospermae da família Cyperaceae, conhecida também como capim-dandá, alho e outros. É uma planta perene, herbácea, ereta, com rizomas e tubérculos de 10 a $60 \mathrm{~cm}$ de altura, originária da Índia e disseminada em mais de 92 países. Propaga-se por semente e principalmente por tubérculos.

É a planta daninha mais disseminada e a mais nociva de todo o mundo, o mesmo ocorrendo nas lavouras do Brasil onde pode ser encontrada em todos os tipos de solo, clima e culturas, exceto em lavouras de arroz inundado. Além de sua grande capacidade competitiva, exerce um efeito inibidor (alelopatia) sobre a brotação de algumas culturas (LO RENZI, 2000). Castro et al. (1983) encontraram que extratos aquosos da parte subterrânea de Cynodon dactylon (grama seda) e Cyperus rotundus (tiririca) inibiram a germinação e o crescimento do to mateiro. Em arroz o efeito foi apenas sobre o desenvolvimento de plântulas. Segundo Vergara e Carvalho (2003), a tiririca, planta de grande dispersão nas áreas de plantio comercial de plantas medicinais, pode prejudicar o estabelecimento da cultura da camomila pelo atraso da germinação de suas sementes.

D entre as plantas medicinais que poderiam ser mais estudadas como alternativas de controle de plantas invasoras encontram-se a carqueja, a mil-folhas e o confrei.

A carqueja (Bacharis trimera (Less) D.C.) é uma planta A ngiospermae, da família A steraceae (compositae), também conhecida como vassoura, tiririca-de-babado e outros (MARTINS et al., 2000). É uma planta perene, subarbustiva, ereta, de caule lenhoso e tri-alado em toda a sua extensão, com 50 a $80 \mathrm{~cm}$ de altura e nativa do Sul e Sudeste do Brasil. Propaga-se principalmente por sementes (LORENZI, 2000). As carquejas ocorrem mais comumente em campos de até $2.800 \mathrm{~m}$ de altitude, florescendo indiferentemente no verão e no inverno (CORRÊA Jr.; MING; SCHEFFER, 1994).

A parte utilizada da carqueja para fins medicinais é a haste e alguns dos seus princípios ativos estão contidos no óleo essencial da planta (PLANTA S MED ICINAIS, 2003). Segundo D epiné (2003), extratos da parte aérea da carqueja apresentaram inibição de germinação de sementes de azevém e picão-preto.

A mil-folhas (A chillea millefolium), planta da família A steraceae (C ompositae) nativa de regiões da Europa, América do Norte, norte da Ásia e sul da Austrália, é conhecida também como aquileia, milem-rama e outros (CORREAA Jr.; MING; SCHEFFER, 1994). É herbácea vivaz com caule subterrâneo (rizo mas) delgado e fibroso. O s caules aéreos alcançam até 60 ou $80 \mathrm{~cm}$ de altura, as folhas são discretas partidas em segmentos muito estreitos que voltam a se dividir, dando ao conjunto um aspecto arrepiado, e a inflorescência tem flores brancas ou rosáceas. Floresce de outubro a março (VERVLOET, 2003).

É uma planta de clima subtropical a temperado e exige luz e calor para a produção dos óleos essenciais. Tolera climas secos e não tolera excesso de umidade e solos encharcados. 0 teor de óleos essenciais varia de acordo com a parte da planta da qual se faz a extração (CORRÊA Jr.; MING; SCHEFFER, 1994). Segundo Maciel et al. (2003), o maior rendimento em óleo encontra-se nas inflorescências, principalmente, e nas folhas.

O confrei (Symphytum officinale L.) é uma planta da família Boraginaceae e também é conhecida como consólida, língua-de-vaca, entre outras. É originária da Ásia, atualmente subespontânea em diversas regiões do mundo, floresce no verão e não produz sementes viáveis no Brasil (CORREA Jr.; MING ; SCHEFFER, 1994). Segundo Martins et al. (2000), é uma planta vivaz, rizomatosa, com parte aérea áspera e pilosa, flores brancacentas, amarelas ou violáceas, folhas basais e caule oco. Seus constituintes químicos principais são a alantoína (cicatrizante e hidratante), alcaloides, taninos, mucilagens, colina, vitaminas, minerais e acido fólico.

As partes utilizadas do confrei são o rizoma, raízes e folhas. As folhas são colhidas de dois em dois meses, a partir do quarto mês e as raízes são coletadas somente no quarto ano, após o plantio, no inverno (durante a renovação da lavoura) (MARTIN; MCCOY; DICK, 1990).

As substâncias oriundas do metabolismo secundário das plantas medicinais podem exercer efeito inibitório sobre plantas invasoras determinando um meio de controle seguro e eficaz delas, podendo se tornar economicamente viável para todos os agricultores, especialmente os pequenos.

Esta pesquisa tem como objetivo determinar a existência de efeito alelopático da carqueja, confrei e mil-folhas em plantas de tiririca. 


\section{MATERIAISE MÉTODOS}

O experimento foi conduzido em casa de vegetação com irrigação automática na Pontifícia Universidade Católica do Paraná situada em São José dos Pinhais, PR, no ano de 2004. As plantas de crescimento espontâneo de carqueja (parte aérea), confrei (parte aérea e parte subterrânea na proporção 1:1) e tiririca (tubérculos), e as plantas cultivadas de mil-folhas (folhas e inflorescências na proporção 1:1) foram coletadas em áreas do mesmo município. Foram realizados três experimentos separadamente para verificação do efeito individualizado de cada planta medicinal sobre o crescimento de plantas de tiririca.

Para cada experimento foram analisados dois fatores. 0 primeiro fator foi a forma de aplicação de cada uma das plantas medicinais: T1 $=$ Testemunha, T2 $=$ Extrato bruto aquoso $\left(200\right.$ g. $\left.\mathrm{L}^{-1}\right), \mathrm{T} 3=$ Plantas picadas em cobertura do substrato, $\mathrm{T} 4=$ Plantas picadas e incorporadas ao substrato e $\mathrm{T} 5=$ Resíduo do extrato aquoso das plantas aplicado em cobertura do substrato. 0 segundo fator estudado foi a época de avaliações (10, 20, 30, 40, 50, 60 dias após instalação). Foram realizadas quatro repetições de cada tratamento.

Para os tratamentos com plantas incorporadas, em cobertura e o resíduo do extrato aquoso foram utilizados 6,1 g de plantas por saco plástico. 0 extrato bruto aquoso foi obtido por turbilhonamento das plantas medicinais (200 g.L.-1) em liquidificador à temperatura ambiente e foram utilizados $30 \mathrm{~mL}$ de extrato por embalagem. O s tubérculos de tiririca (massa média fresca de $0,39 \mathrm{~g}$ e massa média seca de $0,12 \mathrm{~g}$ ) foram plantados de 2 a $3 \mathrm{~cm}$ de profundidade em sacos plásticos preenchidos com $380 \mathrm{~g}$ de areia. Foram utilizados quatro sacos com dois tubérculos cada por parcela experimental, totalizando 80 sacos em cada experimento.

As plantas de mil-folhas foram coletadas no dia 10 de março, as de confrei no dia 6 de maio e as de carqueja no dia 27 de maio. 0 s tubérculos de tiririca foram coletados nos mesmos dias, iniciando, assim, as instalações de cada experimento.

As variáveis analisadas em cada data de avaliação foram a porcentagem de emergência das plantas e o número de folhas por planta. 0 delineamento experimental adotado para os três experimentos foi 0 de blocos casualizados, em um arranjo fatorial (5 x 6) com quatro repetições. As médias dos tratamentos foram comparadas pelo teste de Tukey com significância de 5\% para 0 fator forma de aplicação e pela análise de regressão para o fator época de avaliação.

\section{RESULTADOS}

A planta de mil-folhas, quando picada e incorporada ao substrato, apresentou pequena inibição na emergência da tiririca (Tabela 1), porém, pela análise do número de folhas, verificou-se que houve estímulo ao seu crescimento, gerando plantas com maior número de folhas que a testemunha (Tabela 2).

TABELA 1 - Emergência de plantas de tiririca após diferentes tratamentos com plantas de mil-folhas em casa de vegetação

\begin{tabular}{lc}
\hline Tratamento & Emergência (\%)* \\
\hline Testemunha & $95,0 \mathrm{a}$ \\
Extrato & $94,9 \mathrm{a}$ \\
Cobertura & $89,2 \mathrm{ab}$ \\
Resíduo & $88,1 \mathrm{ab}$ \\
Incorporado & $84,6 \mathrm{~b}$ \\
\hline * Médias seguidas por letras distintas diferem entre si pelo teste de Tukey \\
com significância de $5 \%$.
\end{tabular}


TABELA 2 - Número de folhas por planta de tiririca após diferentes tratamentos com plantas de mil-folhas em casa de vegetação

\begin{tabular}{lllcccc}
\hline Tratamento & \multicolumn{7}{c}{ Avaliações (dias) * } \\
& $\mathbf{1 0}$ & $\mathbf{2 0}$ & $\mathbf{3 0}$ & $\mathbf{4 0}$ & $\mathbf{5 0}$ & $\mathbf{6 0}$ \\
\hline Incorporado & $7,4 \mathrm{a}$ & $9,7 \mathrm{a}$ & $11,5 \mathrm{a}$ & $13,5 \mathrm{a}$ & $14,5 \mathrm{a}$ & $16,8 \mathrm{a}$ \\
Cobertura & $5,1 \mathrm{~b}$ & $8,2 \mathrm{ab}$ & $10,0 \mathrm{a}$ & $12,2 \mathrm{a}$ & $14,2 \mathrm{a}$ & $16,2 \mathrm{a}$ \\
Resíduo & $4,9 \mathrm{~b}$ & $6,2 \mathrm{~b}$ & $7,0 \mathrm{c}$ & $9,2 \mathrm{bc}$ & $11,3 \mathrm{~b}$ & $13,8 \mathrm{~b}$ \\
Extrato & $6,6 \mathrm{ab}$ & $8,0 \mathrm{ab}$ & $8,8 \mathrm{bc}$ & $9,7 \mathrm{~b}$ & $11,0 \mathrm{~b}$ & $12,2 \mathrm{~b}$ \\
Testemunha & $5,2 \mathrm{ab}$ & $6,0 \mathrm{~b}$ & $6,7 \mathrm{c}$ & $6,9 \mathrm{c}$ & $7,6 \mathrm{c}$ & $8,7 \mathrm{c}$ \\
\hline
\end{tabular}

* Médias seguidas por letras distintas nas colunas diferem entre si pelo teste de Tukey com significância de 5 \%.

D esta forma, a planta de mil-folhas não apresentou efeito alelopático significativamente inibidor. Talvez se a planta fosse colhida em outra época ou estádio de floração, ou se fossem utilizadas apenas as inflorescências, pois, segundo Maciel et al. (2003), o maior rendimento em óleo encontra-se principalmente nas inflorescências, a mil-folhas poderia ter apresentado resultados diferentes.

A mil-folhas, como é uma planta exótica, originária de varias regiõ es da Europa, A mérica do Norte, norte da Ásia e sul da Austrália, e não produz sementes viáveis no Brasil (CO RREA Jr.; MING; SCHEFFER, 1994), provavelmente apresenta pequena variabilidade genética entre as plantas, pois sua propagação só é possível por métodos assexuados. Assim, a possibilidade de serem encontrados efeitos alelopaticos significativos com o uso de outras plantas torna-se pequena.

As plantas de confrei quando aplicadas na forma de extrato, resíduo do extrato e em cobertura de substrato diminuíram a porcentagem de emergência da tiririca (Tabela 3), porém quando avaliado o número de folhas por planta conclui-se que o tratamento com plantas picadas em cobertura estimulou a emissão de folhas nas plantas após 60 dias de avaliação, crescendo mais que a testemunha (Tabela 4). O s tratamentos com resíduo e extrato se comportaram iguais à testemunha durante os 60 dias de avaliação, não apresentando estímulo ao crescimento de tiririca. 0 ritmo de emissão de folhas por planta pode ser representado por uma curva de regressão linear significativa (Figura 1).

TABELA 3 - Emergência de plantas de tiririca após diferentes tratamentos com plantas de confrei em casa de vegetação

\begin{tabular}{lc}
\hline Tratamento & Emergência (\%)* \\
\hline Incorporado & $64,5 \mathrm{a}$ \\
Testemunha & $58,8 \mathrm{a}$ \\
Resíduo & $35,9 \mathrm{~b}$ \\
Extrato & $22,9 \mathrm{C}$ \\
Cobertura & $21,8 \mathrm{c}$ \\
\hline
\end{tabular}

Médias seguidas por letras distintas diferem entre si pelo teste de Tukey com significância de $5 \%$.

TABELA 4 - Número de folhas por planta de tiririca após diferentes tratamentos com plantas de confrei em casa de vegetação

\begin{tabular}{llccccc}
\hline Tratamento & \multicolumn{7}{c}{ Avaliações (dias) * } \\
& $\mathbf{1 0}$ & $\mathbf{2 0}$ & $\mathbf{3 0}$ & $\mathbf{4 0}$ & $\mathbf{5 0}$ & $\mathbf{6 0}$ \\
\hline Cobertura & $1,3 \mathrm{a}$ & $4,6 \mathrm{a}$ & $6,7 \mathrm{a}$ & $8,7 \mathrm{a}$ & $13,8 \mathrm{a}$ & $15,4 \mathrm{a}$ \\
Cobertura & $2,5 \mathrm{a}$ & $4,8 \mathrm{a}$ & $7,2 \mathrm{a}$ & $10,9 \mathrm{a}$ & $13,1 \mathrm{ab}$ & $15,3 \mathrm{a}$ \\
Extrato & $2,0 \mathrm{a}$ & $4,7 \mathrm{a}$ & $4,7 \mathrm{a}$ & $7,3 \mathrm{ab}$ & $9,7 \mathrm{bc}$ & $11,0 \mathrm{~b}$ \\
Resíduo & $2,6 \mathrm{a}$ & $4,9 \mathrm{a}$ & $6,2 \mathrm{a}$ & $6,6 \mathrm{~b}$ & $9,6 \mathrm{bc}$ & $11,0 \mathrm{~b}$ \\
Incorporado & $2,6 \mathrm{a}$ & $5,0 \mathrm{a}$ & $6,0 \mathrm{a}$ & $7,7 \mathrm{ab}$ & $8,3 \mathrm{c}$ & $8,9 \mathrm{~b}$ \\
\hline
\end{tabular}

* Médias seguidas por letras distintas nas colunas diferem entre si pelo teste de Tukey com significância de 5 \%. 


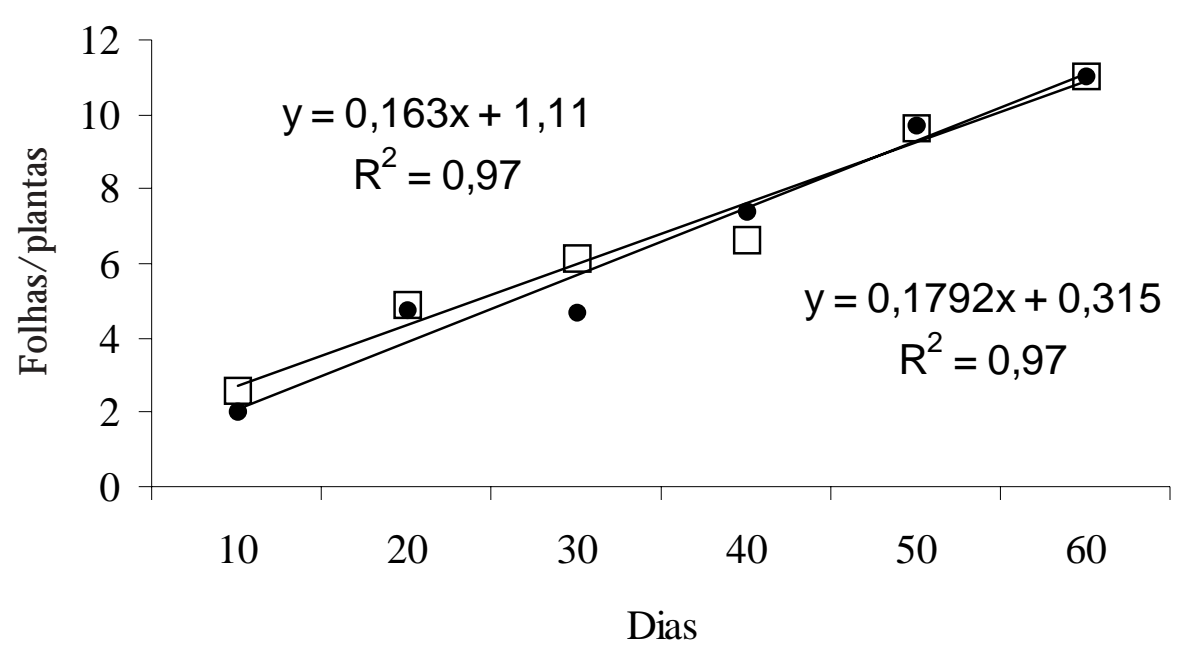

- Extrato $\square$ Resíduo — Linear (Extrato) — Linear (Resíduo)

FIGURA 1 - Número de folhas por plantas de tiririca tratadas com extrato bruto aquoso e resíduo do extrato de plantas de confrei durante 60 dias de avaliação

O confrei, como a mil-folhas, é uma planta exótica, originária da Á sia, e não produz sementes viáveis no Brasil (CORRÊA Jr.; MING; SCHEFFER, 1994). Portanto sua propagação se dá de forma assexuada gerando populações com pequena variabilidade genética, de forma que a otimização dos resultados significativos encontrados possivelmente não seria obtida pela análise de diferentes plantas. Por outro lado, com o estudo realizado com plantas de confrei, utilizando-se proporções diferenciadas entre parte aérea e parte subterrânea, poderiam ser encontrados efeitos alelopáticos ainda mais significativos. D a mesma forma, os resultados poderiam ser maximizados por meio da coleta da planta em outras épocas ou estádios de desenvolvimento, como durante a floração no verão. 0 estudo de métodos de obtenção do extrato bruto aquoso torna-se também importante para se conseguir maior eficiência de extração de compostos ativos com efeito alelopático inibidor.

Plantas de carqueja picadas e incorporadas ou aplicadas em cobertura no substrato, assim como o resíduo do extrato bruto aquoso, proporcionaram menor porcentagem de emergência e menor número de folhas por planta que a testemunha (Tabela 5).

TABELA 5 - Emergência e número de folhas por planta de tiririca após diferentes tratamentos com plantas de carqueja em casa de vegetação

\begin{tabular}{lcc}
\hline Tratamento & Emergência (\%)* & Folhas porPlantas* \\
\hline Testemunha & $65,8 \mathrm{a}$ & $4,0 \mathrm{a}$ \\
Extrato & $62,6 \mathrm{a}$ & $4,9 \mathrm{a}$ \\
Cobertura & $19,3 \mathrm{~b}$ & $2,6 \mathrm{~b}$ \\
Resíduo & $19,0 \mathrm{~b}$ & $2,2 \mathrm{~b}$ \\
Incorporado & $17,2 \mathrm{~b}$ & $2,7 \mathrm{~b}$ \\
\hline
\end{tabular}

Médias seguidas por letras distintas diferem entre si pelo teste de Tukey com significância de $5 \%$. 
Segundo Lorenzi (2000), a carqueja é uma planta nativa do Sul e Sudeste Brasil, propagandose por sementes (de forma sexuada), apresentando grande variabilidade genética entre as plantas. Portanto, diferentemente do confrei e da mil-folhas, o experimento repetido com outras plantas de carqueja poderia gerar resultados diferentes. Uma possibilidade para tentar maximizar esses resultados seria avaliar o efeito alelopático de plantas coletadas em épocas diferentes de maio, mês no qual as plantas foram colhidas para esta pesquisa. O utra possibilidade seria o teste de diferentes temperaturas da água para obtenção do extrato bruto aquoso para se avaliar se esse fator influencia positivamente 0 resultado do efeito alelopático sobre plantas de tiririca.

\section{CONCLUSÕES}

A planta de mil-folhas não apresentou efeito alelopático inibidor, apresentando para 0 tratamento incorporado estímulo à emissão de folhas por planta de tiririca em relação à testemunha.

A planta de carqueja para os tratamentos incorporados, em cobertura e resíduo do extrato bruto aquoso, proporcionou menor porcentagem de emergência de tiriricas e menor número de folhas por planta em relação à testemunha.

Plantas de confrei nos tratamentos resíduo do extrato e extrato bruto aquoso reduziram a porcentagem de emergência de tiriricas sem apresentar estímulo à emissão de folhas na planta.

\section{REFERÊNCIAS}

CASTRO, P. R. C. et al. Efeitos alelopáticos de alguns extratos vegetais na germinação do tomateiro (L ycopersicon esculentum Mill. cv. Santa Cruz). Planta Daninha, Viçosa, v. 6, n. 2, p. 79-85, 1983.

CORREAA Jr., C.; MING , L. C.; SCHEFFER, M. C. Cultivo de plantas medicinais, condimentares e aromáticas. Jaboticabal: FUNEP, 1994.

DEPINÉ, C. E feitos de extrato de carqueja na germinação de sementes de plantas daninhas. 2003. 43 f. Monografia (Bacharelado em Ciências Biológicas) - Núcleo de Ciências Biológicas e da Saúde, Centro Universitário Positivo, Curitiba, 2003.

FERREIRA, A. G. Interferência: competição e alelopatia. In: FERREIRA, A. G.; BO RG HETTI, F. (O rg.). Germinação: do básico ao aplicado. Porto Alegre: Artmed, 2004. p. 251-262.

FERREIRA, G. A.; AQUILA, M. E. A. Alelopatia: uma área emergente da ecofisiologia. Rev. Bras. Fisiol. Veg., São Paulo, v. 12, p. 175-204, 2000. Edição especial.

GO MID E, M. B. Potencialidades alelopáticas dos restos culturais de dois cultivares de canade-açúcar (Saccharum sp), no controle de algumas plantas daninhas. 1993. $96 \mathrm{f}$. Tese (D outorado em Fitotecnia) - Escola Superior de Agricultura Luiz de Queiroz, Universidade de São Paulo, Piracicaba, 1993.

LO RENZI, H. Plantas daninhas do Brasil: terrestre, aquáticas, parasitas e tóxicas. 3. ed. Nova O dessa: Instituto Plantarum, 2000.

MACIEL, M. C. M. et al. Rendimento em óleo essencial de A chillea millefolium cultivada em São José dos Pinhais-PR. In: ENCONTRO SUL-BRASILIEIRO DE PLANTAS MEDICINAIS, 1., 2003, Curitiba. Resumos... Curitiba: G raffiti, 2003. p. 96-106.

MAGALHÃES, A. C.; FRANCO, C. M. Toxicidade do feijão de porco sobre a "Tiririca". Bragantia, Campinas, v. 21, n. 35, p. 53-58, 1962. 
MARTIN, V. L.; MCCOY, E. L.; DICK, W. A. Allelopathy of crop residues influences corn seed germination and early growth. Agron. J., California, v. 82, p. 555-560, 1990.

MARTINS, E. R. et al. Plantas medicinais. Viçosa: Ed. UFV, 2000.

SOUZA FILHO, A. P. S.; ALVES, S. M. Alelopatia: princípios básicos e aspectos gerais. Belém: Embrapa Amazônia O riental, 2002.

VERGARA, A.; CARVALHO, R. I. N. Efeito de extrato de tiririca (Cyperus rotundus) e grama-seda (Cynodon dactylon) sobre a germinação de sementes de camomila (Matricharia chamomilla). In: ENCONTRO SUL-BRASILIEIRO DE PLANTAS MEDICINAIS, 1., 2003, Curitiba. Resumos... Curitiba: Graffiti, 1 CD-ROM.

Recebido: 12/ 11/ 2007

Received: 11/ 12/ 2007

Aprovado: $07 / 05 / 2008$

A pproved: $05 / 07 / 2008$

Revisado: 18/08/2009

R eviewed: 08/ 18/ 2009 